\title{
FORMAÇÃO EM SERVIÇO DE UM PROFESSOR DE MATEMÁTICA REALIZADA PELO COORDENADOR PEDAGÓGICO
}

\author{
Armando Traldi Jr \\ traldijr@gmail.com \\ https://orcid.org/0000-0001-8337-3977 \\ São Paulo, Brasil. \\ Caio Augusto Xavier Fernandes \\ caioaxavier82@hotmail.com \\ https://orcid.org/0000-0001-9983-3050 \\ SEDUC-SP
}

São Paulo, Brasil.

Recibido: 09/11/2020 Aceptado: 01/02/2021

\section{Resumo}

Neste artigo, é apresentada uma formação em serviço, realizada com um professor de matemática e mediada por um professor coordenador (PC). A formação realizada fez parte das atribuições profissionais do PC e, ao mesmo tempo, serviu de objeto de estudo para a pesquisa de mestrado desenvolvida por ele. O objetivo deste artigo é apresentar possibilidades e desafios encontrados pelo PC para realizar as observações em sala de aula e propor o feedback formativo ao professor a partir das observações realizadas na expectativa de constituir uma formação em serviço. Os dados analisados foram coletados a partir do relatório final apresentado pelo PC da pesquisa realizada. Assim sendo, é apresentado um estudo com uma abordagem qualitativa e do tipo documental.. Foram analisados momentos descritos da observação em sala de aula e o feeback formativo descrito no relatório de pesquisa do PC. Após a análise desses elementos, é possível afirmar que a presença do professor coordenador na escola pode contribuir para a realização da formação de professor em serviço, possibilitando focar nos desafios internos à escola, porém, a formação ocorre quando a observação da sala de aula é realizada a partir de fundamentos teóricos e experiências profssisionais bem-sucedidas. Portanto, é relevante que o PC tenha tanto conhecimentos de teorias gerais de educação, de teorias da didática especifica dos compontes curriculares, quanto saberes oriundos de experiências bem-sucedidas, para poder provocar essas reflexões.

Palavras-chave: Formação Contínua. Professor de Matemática. Coordenador Pedagógico. Observação em Sala de Aula.

\section{Resumen}

Este artículo presenta la formación en servicio realizada con un profesor de matemáticas y mediada por un profesor coordinador (PC). La formación realizada formaba parte de las funciones profesionales del PC y al mismo tiempo sirvió como objeto de estudio para la investigación de maestría desarrollada por él. El propósito de este artículo es presentar las 
posibilidades y desafíos que encuentra el PC para realizar observaciones en el aula y proponer retroalimentación al docente de las observaciones realizadas en la expectativa de realizar la capacitación en servicio. Los datos analizados para este artículo fueron recogidos del informe final presentado por el PC de la investigación realizada. Por tanto, este artículo presenta un estudio con enfoque cualitativo y documental. Momnets describió a partir de la observación en el aula y se analizaron las reacciones realizadas en el informe de investigación del PC. Luego de analizar estos elementos, es posible afirmar que la presencia del docente coordenador en la escuela puede contribuir a la realización de la formación docente en servicio, posibilitando enfocar los desafíos internos de la escuela, sin embargo la formación ocurre cuando además de la observación hay reflexiones basadas en teorías o en otras diferentes experiencias exitosas. Por tanto, es relevante que el PC cuente tanto con conocimientos de teorías generales de la educación, teorías de didácticas específicas de componentes curriculares, como con conocimientos de experiencias exitosas, para provocar estas reflexiones.

Palabras clave: Formación Continua. Profesor de Matemáticas. Coordinadora Pedagógica. Observación en el Aula.

\begin{abstract}
This article presents in-service training carried out with a mathematics teacher and mediated by a coordinating teacher (PC). The training carried out was part of the professional duties of the $\mathrm{CP}$ and at the same time served as an object of study for the master's research developed by him. The objective of this article is to present possibilities and challenges encountered by the PC to carry out observations in the classroom and to propose feedback to the teacher of the observations made in the expectation of carrying out in-service training. The data analyzed for this article were collected from the final report presented by the PC of the research carried out. Therefore, this article presents a study with a qualitative and documentary approach. Momnets described from observation in the classroom and the feebacks carried out in the PC research report were analyzed. After analyzing these elements, it is possible to affirm that the presence of the collaborating teacher in the school can contribute to the realization of teacher coordinator in service, making it possible to focus on the internal challenges of the school, however the training occurs when in addition to observation there are reflections based on theories or in other different successful experiences. Therefore, it is relevant that the PC has both knowledge of general theories of education, theories of specific didactics of curriculum components, and knowledge from successful experiences, in order to provoke these reflections.
\end{abstract}

Keywords: Continuous Formation. Maths Teacher. Pedagogical Coordinator. Classroom Observation.

\title{
Introdução
}

Há um consenso entre os pesquisadores da área da Educação sobre a escola ser um ambiente dinâmico e propício para se desenvolver a formação de professor e produzir novos 
conhecimentos, pois é nela que surgem as reais necessidades das demandas da sala de aula, e, por consequência, momentos propícios para refletir sobre o processo de ensino e aprendizagem.

É nessa expectativa que muitas redes de ensino, públicas e particulares, no Brasil, têm a figura profissional do coordenador pedagógico, que tem entre suas funções a de proporcionar ao professor momentos de reflexão sobre experiências educacionais, criando, assim, no próprio ambiente de trabalho, o que é definido por alguns teóricos como sendo uma "formação em serviço".

Tal formação é uma estratégia promissora, como afirma Candau (2003, p. 57):

Na experiência dos professores, o dia-a-dia na escola é um locus de formação. Nesse cotidiano, ele aprende, desaprende, reestrutura o aprendido, faz descobertas e, portanto, é nesse locus que muitas vezes ele vai aprimorando a sua formação. Nesse sentido, considerar a escola como locus de formação continuada passa a ser uma afirmação fundamental na busca de superar o modelo clássico de formação continuada e construir uma nova perspectiva na área de formação continuada de professores. Mas este objetivo não se alcança de uma maneira espontânea, não é o simples fato de estar na escola e de desenvolver uma prática escolar concreta que garante a presença das condições mobilizadoras de um processo formativo. Uma prática repetitiva, uma prática mecânica não favorece esse processo.

As ideias de Nóvoa (2002) sobre a formação de professores na própria escola coadunamse com as de Candau, para aquele autor, a formação em serviço promove no docente uma reflexão sobre a prática, passando a ser uma oportunidade de formação realizada "pela experimentação, pela inovação, pelo ensaio de novos modos de trabalho pedagógico", e ainda afirma que a experiência, por si só, não é nem formadora nem produtora de conhecimento, quando não vem acompanhada por reflexões que possibilitam, assim, a produção de novos conhecimentos, facilitando a formação.

Para Gouveia e Placco (2013), o Coordenador Pedagógico pode ser a peça central para criar esses momentos de reflexão, pois é ele que está na escola, acompanha o professor e que pode firmar uma boa parceria de formação.

Almeida e Placco (2009, p. 3) explicita a função de formador do coordenador pedagógico:

Como formador, compete-lhe oferecer condições ao professor para que se aprofunde em sua área específica e trabalhe bem com ela; como transformador, cabe-lhe o compromisso com o questionamento, ou seja, ajudar o professor a ser reflexivo e crítico com a sua prática. 
Pode-se afirmar, assim, a partir dos estudos de Candau, Nóvoa, Gouveia, Almeida e Placco, que a formação em serviço, quando ocorre em parceria entre professor coordenador (PC) e professores, pode ser uma promissora estratégia de formação para melhoria da qualidade de ensino e aprendizagem nas escolas.

De acordo com Fernandes e Traldi (2021) há estudos desenvolvidos no Brasil, principalmente a partir de 2000, que buscam compreender como essas formações ocorrem quando há a presença do professor coordenador nas escolas da educação básica. Os estudos, por exemplo, de Souza (2017), de Sampaio (2018) e o de Oliveira (2018), investigaram a função do coordenador pedagógico nas escolas, considerando aspectos das suas funções de trabalho e ações relacionadas à formação de professores.

Os autores afirmam que esses estudos destacaram que as formações realizadas por esses profissionais, geralmente, abordam temáticas internas à escola, dando um maior significado e sentido às formações, pois os participantes da formação enfrentam os desafios parecidos e os locais de trabalho têm a mesma infraestrutura. Outro aspecto relevante é ter previsto na grade horária desses profissionais um espaço de tempo para os encontros.

Os desafios listados nesses estudos, por outro lado, estão relacionados com a falta de tempo para o PC preparar essas formações, visto que esse profissional tem uma série de outras atribuições, como: atendimento aos pais, orientação aos alunos, suporte ao professor, relação direta com equipe gestora, preparo de reuniões; além desse, o fato do coordenador pedagógico não ter na sua graduação nem na sua rotina de trabalho espaço e tempo reservados para sua própria formação como formador de professor.

Apesar dos desafios postos ao PC para exercer a função de formador, é possível de afirmar-se que o PC tem um grande potencial para ser um formador de professor, contribuindo com a qualidade da educação, mas se faz necessário o desenvolvimento de estudos que busquem ampliar os conhecimentos referentes à parceria entre PC e professores na expectativa, fazendo com que dessa parceria surjam formações qualificadas à melhoria do ensino.

Foi nesse sentido que Fernandes (2021), desenvolveu o estudo intitulado "Formação em serviço de um professor de matemática mediada pelo professor coordenador" com o objetivo de compreender possibilidades e desafios de realizar uma formação em serviço para um professor de matemática mediada pelo professor coordenador (PC), concebida a partir das observações da sala de aula e, que nesse artigo, será objeto de estudo. 
Sendo assim, neste artigo é proposta uma ampliação do que foi realizado no estudo de Fernandes (2021), que é um dos autores deste artigo, em especial, descrevendo a análise feita a partir das estratégias de observação em sala de aula e feedback formativo.

\section{Formação em Serviço}

Ao longo das décadas de 1980 até 2020, as concepções de formação de professores foram tomando diferentes vieses, principalmente após as publicações dos estudos de Schon (1987), os quais valorizam os saberes da prática no desenvolvimento profissional do professor.

É na continuação dessa trajetória que outros autores como Nóvoa (2002) e Kramer (1993) destacam a importância de ver o professor como construtor dos saberes inerentes à profissão da docência, destacando que faz parte desses saberes, além dos conhecimentos científicos, os conhecimentos culturais e sociais, que, na maioria das vezes, são vividos dentro do ambiente escolar.

Portanto, pode-se compreender que a escola é um ambiente favorável à produção de conhecimentos, visto que é nela que estão presentes as diferentes culturas. Como afirma Nóvoa (2002), porém, não é só o fato de vivenciar a experiência que se concretiza a produção do conhecimento, se faz necessário refletir, também, sobre essas experiências.

É na busca deste momento de reflexão que muitas redes de ensino criaram na grade horária do professor um espaço para que houvesse encontros coletivos entre professores e coordenadores pedagógicos, para refletir sobre as práticas desenvolvidas e, por consequência, criar um ambiente favorável para formação em serviço dos professores.

$\mathrm{Na}$ expectativa de compreender melhor as necessidades para que ocorra a formação em serviço, Placco (2002) destaca que essa formação precisa: (i) estar atrelada ao projeto político pedagógico; (ii) ser planejada de forma coletiva; (iii) ter espaços e tempos para que ocorra a participação de todos, como a reflexão da docência e experiência profissional; (iv) que o compromisso seja não apenas dos gestores, mas dos educadores também.

Pode-se afirmar então que a formação em serviço vai além da melhoria na prática pedagógica do professor, pois busca atender às demandas e necessidades do meio em que aquele professor atua, de forma a colaborar com todo o processo pedagógico da escola, melhorando a qualidade da educação. 
Para Freire (2001)

\begin{abstract}
A melhora da qualidade da educação implica a formação permanente dos educadores. E a formação permanente se funda na prática de analisar a prática. É pensando sua prática, naturalmente com a presença de pessoal altamente qualificado, que é possível perceber embutida na prática uma teoria ainda não percebida ainda, pouco percebida ou já percebida, mas pouco assumida. ( p. 72).
\end{abstract}

Nóvoa (2002) contribui com essa discussão na sua obra intitulada: "Formação de professores e trabalho pedagógico", destacando aspectos que devem estar presentes na formação continuada:

- $\quad$ alimentar-se de perspectivas inovadoras, que não utilizem preferencialmente "formações formais", mas que procurem investir do ponto de vista educativo as situações escolares.

- valorizar as atividades de (auto) formação participada e de formação mútua, estimulando a emergência de uma nova cultura profissional no seio do professorado.

- $\quad$ alicerçar-se numa "reflexão na prática e sobre a prática", através de dinâmicas de investigação - ação e de investigação - formação, valorizando os saberes de que os professores são portadores.

- $\quad$ incentivar a participação de todos os professores na concepção, realização e avaliação dos programas de formação contínua e consolidar redes de colaboração e espaços de parceria que viabilizem uma efetiva cooperação institucional.

- capitalizar as experiências inovadoras e as redes de trabalho que já existem no sistema escolar, investindo-as do ponto de vista de sua transformação qualitativa, em vez de instaurar novos dispositivos de controle e de enquadramento.

Em síntese, o autor afirma que as situações escolares devem ser o eixo organizador das formações, portanto, a escola passa a ser o ambiente mais indicado para que ocorra as formações. Deve-se valorizar a auto formação, as reflexões da prática do docente e fazer com que ocorra a participação de todos os professores, valorizando os conhecimentos e práticas já consolidadas por eles. 
Assim, para este artigo, uma das possibilidades de "formação em serviço" é entendida como o momento em que o PC e o professor de matemática, juntamente, se disponibilizam a refletir sobre as ações desenvolvidas pelo professor durante as aulas observadas pelo PC.

\section{O estudo analisado: formação em serviço de um professor de matemática mediada pelo professor coordenador}

Neste artigo, serão analisados dois aspectos da pesquisa, que foi desenvolvida no período de agosto de 2018 a setembro de 2020, sobre as observações que ocorreram na sala de aula e o feedback formativo realizado após as observações. Portanto, o estudo proposto neste artigo é de abordagem qualitativa e do tipo documental, pois terá como objeto de estudo o relatório final de Fernandes (2021).

A seguir, serão destacados elementos do estudo que foi objeto de análise neste artigo, para uma melhor compreensão do cenário que está posto este trabalho.

- $\quad$ Metodologia e procedimentos metodológicos do estudo de Fernandes (2021):

O estudo analisado teve uma abordagem qualitativa, pois o objetivo da investigação era entender o processo sobre o qual ocorreu a formação, também pode-se afirmar que foi do tipo pesquisa-ação, pois o PC, que fez parte da pesquisa, era também o pesquisador.

Também é relevante destacar que o estudo desenvolvido teve aspectos do tipo de pesquisa denominada interpretativa, que segundo Cassiani (1996), deriva do reconhecimento básico dos processos interpretativos e cognitivos inerentes à vida social e enfatizados nessas abordagens, pois não parte de pressupostos teóricos pré-estabelecidos, mas daqueles evidenciados durante a coleta de dados, características essas que estão presentes no estudo analisado.

- $\quad$ A escola em que foi desenvolvido o estudo

A pesquisa ocorreu em uma escola pública estadual, situada na cidade de Atibaia/SP, localizada na região central, onde durante o dia funciona o Programa Ensino Integral (PEI), com quatorze turmas, sendo nove turmas do ensino fundamental anos finais e cinco do ensino médio. No período noturno, por sua vez, a escola funciona com dez salas, sendo uma turma da $2^{\mathrm{a}}$ série do ensino médio regular e nove turmas da educação de jovens e adultos do ensino médio. Com 
relação aos materiais didáticos disponíveis, a escola tem em seu acervo: livros didáticos de todos os componentes curriculares; material "São Paulo faz escola", distribuído pela Secretaria da Educação (SEDUC) e o material "EJA Mundo do Trabalho", um material específíco e destinado ao público da EJA.

A observação da aula do professor foi em uma turma de $3^{\circ}$ Termo, composta por vinte e nove alunos, e nos dias em questão estavam presentes em média vinte alunos. O critério para que a observação fosse realizada nessa turma foi pela sugestão do professor, que apontou a determinada turma como a mais participativa, além de estar com o conteúdo em dia. Acreditamos que essas características poderiam colaborar com a pesquisa e as observações a serem feitas.

\section{- $\quad$ O professor coordenador (PC)}

O professor coordenador, sujeito dessa pesquisa, atua na função de coordenador pedagógico desde outubro de 2017 e é formado em licenciatura matemática e pedagogia. Atua na rede estadual desde agosto de 2012. Tem experiência profissional como professor no ensino fundamental anos finais e ensino médio, e na educação de jovens e adultos.

\section{- $\quad$ O professor de matemática}

O professor participante da pesquisa é formado em Licenciatura em Matemática desde 2013. Atua há oito anos no magistério público e privado, tendo iniciado sua carreira no setor privado. Este é o terceiro ano atuando na escola que faz parte dessa pesquisa. Atualmente, ele trabalha como contratado na rede pública estadual e na rede privada. Com relação à experiência com a modalidade EJA, este é o quarto ano que ele atua com esse público. A escolha desse profissional se deu: por ser da mesma área de formação que o PC, pela carga horária que possui; por estar na escola todas as noites; e pela experiência profissional com a educação de jovens e adultos.

\section{Apresentação e análise dos dados}


Neste artigo, foram analisados dois momentos da pesquisa realizada por Xavier (2020):

- $\quad$ observação das aulas: o PC assistiu às aulas do professor de matemática focando os seguintes aspectos: (i) o conteúdo da aula; (ii) a organização e gestão; (iii) as estratégias de ensino e; (iv) a interação. Foram observadas quatro aulas de 45 minutos, ao longo de duas semanas, nas quais foram tratados os seguintes conteúdos: introdução à probabilidade e probabilidades geométricas. Para realizar e registrar as observações, foram utilizadas as estratégias de gravação de áudio e transcrição dos diálogos que ocorreram nas aulas observadas e sínteses elaboradas após cada aula observada, constituindo o diário de bordo.

- realização do feedback formativo: foi realizado entre o PC e o professor de matemática em duas sessões de uma hora cada. A conversa foi pautada nas observações e registros feitos das aulas e essas sessões também foram gravadas e transcritas pelo PC. Vale ressaltar que o PC produziu também um diário de bordo, que serviu para registrar as observações do pesquisador, tanto no momento observações em sala de aula, quanto no o momento do feedback formativo.

\title{
Unidades de análise: observações em sala de aula e Feedback das observações
}

A observação de aulas é uma atividade que pode ter um papel de grande importância na melhoria da qualidade do ensino e da aprendizagem. De acordo com Reis (2011)

\begin{abstract}
Especialmente durante as duas últimas décadas, tem-se verificado uma tendência internacional e nacional para encarar a observação de aulas como um processo de interação profissional, de caráter essencialmente formativo, centrado no desenvolvimento individual e coletivo dos professores e na melhoria da qualidade do ensino e das aprendizagens (p.11).
\end{abstract}

Para esse autor, a observação pode ser utilizada para diferentes finalidades, tais como: “... demonstrar uma competência, partilhar um sucesso, diagnosticar um problema, encontrar e testar possíveis soluções para um problema, explorar formas alternativas de alcançar os objetivos curriculares, aprender... (Reis, 2011, p.12).

Ele destaca, ainda, que a observação pode ser informal, quando é de curta duração, feita por supervisores, ou diretores, com os objetivos de verificar práticas desenvolvidas, valorizar práticas bem-sucedidas, ou para proporcionar apoio ao docente; ou formal, que diferente da informal, inclui uma preparação e planejamento da observação, este tipo de observação, para 
Reis, é "fortemente influenciada pelo modelo de supervisão clínica e envolve a repetição cíclica de uma sequência de fases" (Reis, 2011, p.15).

As fases que Reis destaca da observação como estratégia de formação são: (i) uma sessão antes de realizar a observação com a finalidade de conhecer os objetivos e as estratégias de ensino para aula, além de ser estabelecido os focos específicos e procedimentos da observação; (ii) a observação da aula; (iii) a leitura e análise dos dados observados; (iii) a sessão pósobservação, que possibilita a reflexão crítica do que foi observado, assim como a identificação de aspectos positivos e aspectos que precisam ser melhorados; e (iv) avaliação global do processo de avaliação.

Essas fases destacadas por Reis foram contempladas no estudo realizado, pois houve um primeiro momento que o PC decidiu o que seria observado a partir das demandas da SEE; depois foram feitas as observações na sala de aula; a transcrição do material gravado seguido de uma descrição teve o momento do feedback formativo, juntamente com o professor; e, por fim, a escrita das considerações levando em conta todos esses momentos. Além das fases presentes, pode-se afirmar que a observação realizada foi do tipo formal, pois realizada pelo PC que tem o cargo de coordenador pedagógico na escola em que aconteceu o estudo, e as observações e os feedback formativos se repetem em vários momentos no decorrer do ano letivo.

Para ilustrar a análise apresentada neste artigo, foram destacados três diferentes trechos, destacando os momentos de observação e feedback formativo relacionado ao tema: (i) trecho 1: envolvimento dos estudantes; (ii) trecho 2: articulação entre os conceitos estudados e; (iii) trecho 3: conteúdos e habilidades abordados na aula.

Quadro: trecho 1

Trecho 1: Observação com o foco de verificar se há o envolvimento dos alunos em aula

Alunos começam a discutir a definição de número primo e questionam para o professor: " O número primo é aquele que divide por ele mesmo e por um?"

Professor: Só.

[Dois alunos ao fundo da sala, começam a verificar quem são os números primos entre 1 a 50 . Vão dizendo cada número verificando e contando na mão para anotar.]

Aluno: Professor 7 é número primo? 
Professor: Divida o número 7 por ele e por 1 , o resultado tem que dá número inteiro.

Aluno: Da 7 e 1.

Professor: O 7 dá para dividir por outro número?

Aluno: Não.

Professor: Então é número primo

[observação da aula do dia 21/10/2019]

\section{Anotações no diário de bordo do PC:}

No trecho acima, podemos perceber que há diálogos e interações dos alunos entre si, e dos alunos com o professor. Estes diálogos estão todos relacionados com o conteúdo da aula, neste caso, sobre definição de números primos, que era um dos itens de um exercício.

É relevante observar se ocorrem esses diálogos e interações, pois é a partir deles que se percebe o entrosamento dos alunos com a aula, se estão participando ativamente, se há interesse sobre o que está sendo exposto pelo professor. Ressalta-se que neste trecho recortado não foi feita a discussão do encaminhamento da resposta do professor, questionando se era possível dividir o 7 por 1 e por ele mesmo, característica não específica para o conjunto dos números primos.

\section{Feedback Formativo}

O PC inicia a conversa com o professor explicando que o feedback a ser realizado será pautado nas quatro aulas observadas na turma de $3^{\circ}$ termo da EJA do Ensino Médio. Comenta que pode ser observado que o professor tem um bom relacionamento com os alunos; realiza intervenções quando se faz necessário e que utiliza o material "EJA Mundo do Trabalho", que é uma recomendação da SEDUC, por ser um material recomendado aos alunos da Educação de Jovens e Adultos. O professor comenta que estas características se dão pelo fato de lecionar para a mesma turma desde o semestre anterior, portanto já conhece os alunos há algum tempo.

Fonte: elaborado pelos autores

No trecho-1, é possível perceber que o PC destacou um diálogo entre professor e aluno, na expectativa de destacar durante o feedback a importância da interação na sala de aula. Há autores como Oliveira (2002), que afirmam a importância de o professor questionar os alunos na expectativa de motivá-los a participarem da aula.

Assim o PC inicia o feedback formativo destacando esse e outros aspectos como positivos na forma do professor conduzir a aula, evitando de focar os aspectos considerados pelo PC como equívoco do professor. Essa escolha mostra que sua opção foi a de encaminhar o 
feedback de acordo com o tipo de feedback confirmativo, defino por Kurtoglu-hooton (2004) como sendo o feedback que informa o professor que ele está seguindo o percurso esperado para concretizar os objetivos propostos. Os estudos desenvolvidos por (Bushman, 2006) destaca que esse reconhecimento por parte do observador pode trazer impactos positivos no desenvolvimento profissional do professor observado.

Quadro: trecho 2

Trecho 2: observar se são estabelecidas pelo professor articulações entre os conceitos abordados e outros temas

Nesta unidade, foram observadas situações em que o professor traz algo extra para a aula ou até mesmo conteúdos anteriores para fazer ligações. A seguir, são apresentados alguns trechos das falas do professor, fazendo relação do conteúdo desenvolvido, com um projeto que realizaram no semestre anterior.

Aluna: Professor eu tenho uma dúvida. De onde o senhor tirou esse 5000? 60 vezes x 5000? [aluna referindo-se à anotação que o professor fez em lousa]

Professor: observe que tem a setinha aqui, 360 vezes $\mathrm{x}, 360 \mathrm{x}$, 50 vezes 100,5000 . Multiplica em cruz. No semestre passado quando a gente fez a feira cultural, lembra das exposições que fizemos, vocês fizeram os gráficos, se a gente fosse fazer gráfico de circunferências, setores, a gente teria trabalhado para fazer esses valores para compensar o outro, lembra que tantos por centos valia cada coluna, cada tabela, você conseguia montar desse jeito também aqui, gráfico de setor, aí você pegava lá quantos por cento tinha $60 \%$ de crime, de homofobia. Se a gente fosse fazer desse jeito a gente pegaria o $60 \%$, achar quantos graus tem e marcar certinho quantos graus tem e também daria pra fazer desse jeito. Que é de setor ou de pizza. Você viu galera isso é fácil, daria pra gente fazer, sei lá, na nossa feira.

[observação da aula do dia 23/10/2019]

\section{Anotações no diário de bordo do PC:}

Nessa aula, observou-se que o professor comenta sobre porcentagem, sobre proporcionalidade e relaciona com o conteúdo que os alunos trabalharam em forma de projeto em uma feira cultural realizada na escola. Nesta feira, os alunos tinham um tema central e a partir deste realizavam pesquisas e apresentavam à comunidade escolar. A parte de matemática nas atividades desenvolvidas na feira foi a elaboração de gráfico. $\mathrm{O}$ professor aproveita desse fato para responder à questão do aluno fazendo referência a essa atividade. 
Tratar sobre contextualização em sala de aula é um assunto que deve ser levado em pauta, visto que as atuais orientações reforçam a necessidade deste ato e apontam a importância de se contextualizar, porém, vale destacar que o simples fato de afirmar que há a relação entre dois temas, como o de porcentagem com a construção de gráficos de setores, não se caracteriza a ligação entre os temas abordados, seria necessário que o professor explicitasse a "ligação", além de verificar se o estudante entendeu. Deixar a cargo do estudante a articulação pode não alcançar o objetivo de se concretizar na prática essa articulação.

\section{Feedback formativo}

O PC pergunta se além dos temas explorados durante as aulas sobre probabilidade, o professor poderia ter abordados outros temas.

PC: E você acha que poderiam ter outros conteúdos abordados, outras partes da probabilidade, que não foram, que o livro não trouxe e poderiam ter sido passado para eles?

Professor: Poderia. Mas, eu não alcançaria o total da sala. E ficaria um pessoal lá, que iria ficar um pouco para trás, que não conseguiria entender! Mas coisa mínima, em torno de $10 \%$ no máximo!

PC: Certo! Porque tem outros tipos de probabilidade e conteúdo, como: probabilidade com evento repetido, eventos independentes, multiplicação de probabilidades, união de dois eventos que não foram abordados. Então, você acha que...

Professor: Então, até porque a apostila ela não aborda, é...essa...essa parte. Fica mais restrita.

PC: Tá! E se nós tivéssemos um material complementar? Você acha que daria conta?

Professor: Sim!

E o docente, mais uma vez, justifica que sim, mas não atingiria todos os estudantes da sala, somente uma minoria conseguiria acompanhar, além do material utilizado não abordar tais conteúdos. $\mathrm{O}$ docente afirma, no entanto, que se adotasse um material complementar ao do "EJA Mundo do Trabalho", poderia ter tratado de forma diferente o conteúdo estudado.

Percebe-se que é recorrente o professor falar sobre a dificuldade dos alunos, no entanto, é um equívoco do docente olhar apenas para a dificuldade dos estudantes e não levar em conta o aprofundamento de conhecimento dos demais alunos. Durante as aulas observadas, foi percebido pelo PC que muitos estudantes apresentavam conhecimentos prévios do conteúdo estudado quando questionado pelo professor e que havia outros estudantes interessados em aprender mais sobre o assunto, que era os que demonstravam mais facilidade em resolver os exercícios propostos.

Fonte: elaborado pelos autores 
No trecho 2, é destacada a discussão sobre a "articulação de diferentes temas na aula", que é uma estratégia importante a ser desenvolvida pelos professores, pois possibilita que o estudante dê mais significado aos conteúdos estudados, se sintam mais motivados, conforme é revelado em estudos como o de (Fazenda (1979); D'Ambrosio (2012)).

Nesse trecho, porém, foi possível perceber que o PC não teve a habilidade de conduzir a discussão para o tema pretendido, aceitou a justificativa do professor desviando o assunto para a dificuldade dos estudantes. Isso revela que apesar da observação estar destacada para a “articulação entre conceitos" e ter elementos da sala de aula que promova tal discussão, é necessário que o PC seja insistente na forma de abordar o assunto, caso contrário, a meta de provocar a reflexão sobre a articulação não ocorre durante o momento do feedback formativo.

Para Nóvoa (2002), este momento de feedback é o que caracteriza uma formação fundamentada na experiência de sala de aula, no entanto, observa-se que é necessário que o PC tenha leituras teóricas sobre o tema para poder problematizar e propiciar um ambiente de formação ao professor. Caso contrário, a discussão pode ficar posta de forma superficial, não propiciando a reflexão e como consequência não efetivando a formação.

Quadro: trecho 3

Trecho 3: conteúdos e habilidades abordadas em sala de aula

Em relação as habilidades e competências previstas na proposta Curricular de São Paulo (2008), envolvendo o conteúdo de probabilidade no Ensino Médio, temos:

Quadro 12 - Conteúdos e Habilidades referentes à probabilidade na Proposta Curricular de São Paulo

\begin{tabular}{|c|c|}
\hline Conteúdos & Habilidades \\
\hline $\begin{array}{l}\text { Probabilidade simples } \\
\text { • Arranjos, combinações e } \\
\text { permutações } \\
\text { • Probabilidade da reunião } \\
\text { e/ou da intersecção de eventos } \\
\text { • Probabilidade condicional } \\
\text { • Distribuição binomial de } \\
\text { probabilidades: o triângulo de } \\
\text { Pascal e o binômio de Newton }\end{array}$ & $\begin{array}{l}\text { Saber calcular probabilidades de eventos } \\
\text { em diferentes situações-problema, recorrendo a } \\
\text { raciocínios combinatórios gerais, sem a } \\
\text { necessidade de aplicação de fórmulas específicas. } \\
\text { Saber resolver problemas que envolvam o } \\
\text { cálculo de probabilidades de eventos simples } \\
\text { repetidos, como os que conduzem ao binômio de } \\
\text { Newton. } \\
\text { Conhecer e saber utilizar as propriedades } \\
\text { simples do binômio de Newton e do triângulo de } \\
\text { Pascal. }\end{array}$ \\
\hline
\end{tabular}

Fonte: Documento oficial do governo do Estado de São Paulo. Disponível em: http://www.educacao.sp.gov.br 


\section{Anotações no diário de bordo do PC:}

Observou-se, no entanto, que o professor abordou nas aulas apenas a habilidade de "saber resolver problemas que envolvam ideias simples sobre probabilidade (porcentagem que representa possibilidades de ocorrência)" (DE SÃO, 2008, p. 60), que é uma habilidade prevista para os anos finais do ensino fundamental. As habilidades, como: probabilidade da reunião e/ou da intersecção de eventos, probabilidade condicional, que são recomendadas para o Ensino Médio não foram abordadas nas aulas observadas.

Portanto, outro assunto relevante para a pauta formativa é a seleção dos conteúdos a serem tratados na modalidade EJA do nível Ensino Médio.

\section{Feedback formativo}

Trecho recortado: conteúdos e habilidades abordados em sala de aula

PC: Você acha que poderiam ter outros conteúdos abordados, outras partes da probabilidade, que não foram, que o material não trouxe e poderiam ter sido discutido com os alunos?

Professor: Poderia. Mas, eu não alcançaria o total da sala. E ficaria um pessoal lá, que iria ficar um pouco para trás, que não conseguiria entender! Mas, coisa mínima, em torno de $10 \%$ no máximo!

PC: Certo! Tem outros tipos de probabilidade e conteúdo, como: probabilidade com evento repetido, eventos independentes, multiplicação de probabilidades, união de dois eventos que não foram abordados. Então, você acha que...

Professor: Então, até porque a apostila ela não aborda, é...essa...essa parte. Fica mais restrita.

PC: Ok! E se nós tivéssemos um material complementar? Você acha que daria conta?

Professor: Sim!

PC: Agora, falando em habilidade, eu tenho uma habilidade no currículo que é a seguinte: "Saber resolver problemas que envolvam o cálculo de probabilidades de eventos simples repetidos, como os que conduzem ao binômio de Newton". Essa habilidade não aparece nas suas aulas.

Professor: Não, não aparece!

PC: Você considera que seria possível trabalhar essa habilidade com as turmas da EJA?

Professor: Hum... não. 


\section{PC: Não?}

Professor: Não... eu creio que não.

PC: E em uma turma do ensino regular? Seria possível?

Professor: Sim! Com mais tempo de trabalho, conseguindo abordar mais exercícios e tendo um livro com mais atividades, acredito que sim. trabalhar?

PC: Então, no ensino regular você acha que é possível

Professor: Sim!

PC: E na EJA, por que você acha que não dá para trabalhar?

Professor: Tempo curto, nosso tempo de aula, duração semestral é mais curto. Ah... os alunos eles têm um pouco de defasagem, não a maioria, mas uma parcela bem significativa, em termos de: interpretação de texto, leitura para eles nesse contexto seria um pouco mais trabalhoso. Daria certo, se a gente tivesse um pouco mais de tempo.

PC: Certo.

Professor: Mas, eu acho que pela falta de tempo, por exatamente ser muito corrido, a gente não consegue abordar todo o conteúdo.

PC: Então, alguns alunos daquela sala em questão. Se trabalhasse essa habilidade, alguns alunos iriam conseguir?

Professor: Sim!

PC: Outros não?

Professor: Não, não conseguiria!

PC: Mas se houvesse um tempo maior, você conseguiria atingir também esses alunos também com aprendizagem?

Professor: Sim. Porque a gente conseguiria mostrar como funciona, passar na prática, passar atividades, consigo passar mais atividades em lousa e daria para atingir eles sim.

Com relação à habilidade prevista no currículo para o Ensino Médio, o docente relata que pelo fato das turmas da EJA serem semestrais, a carga horária desta modalidade ser menor do que das turmas regulares, dificulta a abordagem de algumas habilidades, além da defasagem presente nas turmas da Educação de Jovens e Adultos.

O professor, durante a formação, mostrou ter uma visão equivocada do que é o ensino na EJA. Pois, em suas falas ele demonstra que a EJA é um resumo do regular, e não uma 
modalidade diferenciada. Não usar uma abordagem diferenciada, pautada na vida profissional dos estudantes, é desconsiderar toda trajetória e experiência que esses alunos possuem.

Durante a formação, o PC não conseguiu conduzir a conversa para tratar desse assunto com o professor. Foi à busca de um texto, porém, e recomendou a leitura do artigo: "Reflexões acerca da organização curricular e das práticas pedagógicas na EJA", de autoria da professora adjunta da Universidade Estadual do Rio de Janeiro (UERJ), Inês Barbosa de Oliveira.

Fonte: elaborado pelos autores

No trecho -3, o professor utiliza para justificar o porquê de não ter tratado determinados conteúdos fundamentados em concepções sobre a modalidade EJA, que já foram contestadas em diferentes estudos (Fonseca, 2012); (Silva e Traldi, 2019) e Freitas (2013). Ele justifica, por exemplo, que não aborda um determinado conteúdo, que está proposto para aquele nível de ensino, alegando que alguns alunos teriam dificuldades. Em diversos estudos é revelado que muitas vezes que o professor afirma que o estudante tem dificuldade em aprender um determinado conteúdo é pelo fato dele não ter a compreensão desse conteúdo. Demo (2018) afirma que "Se quisermos melhorar a aprendizagem dos alunos, há que promover a aprendizagem do professor" (p.18).

Outra concepção revelada pelo professor no diálogo é a exclusividade do uso de um determinado material didático, justificando que não ensina determinado conteúdo ou abordagem por não estar presente naquele determinado material didático, mas ao mesmo tempo deixa de trabalhar com determinado conteúdo alegando a falta de tempo. Há uma contradição nesses dois posicionamentos, o material tem que ser seguido literalmente somente em determinadas situações.

Também fica explicita na fala do professor a concepção de que há diferença entre os conteúdos para o ensino na modalidade EJA e os selecionados para o ensino regular, e essa diferença está relacionada ao tempo de duração desses cursos e não das características especificas e conhecimentos de vida diferentes que os estudantes da modalidade EJA tem em relação aos estudantes do ensino regular. Pode-se entender na fala do professor que os conteúdos da EJA têm que ser condensados, se compararmos ao ensino regular.

E, por fim, pode-se destacar a concepção de que o estudante da EJA tem "defasagens" diferentes e mais complexas que os estudantes do ensino regular.

Vale ressaltar que em relação ao feedback formativo, apesar do PC ter tido a percepção dessas concepções equivocadas do professor, visto que abordou os assuntos, não 
aproveitou em nenhum momento para propor reflexões sobre elas. Sendo assim, pode-se afirmar que não houve uma reflexão fundamentada em outras experiências bem-sucedidas ou na literatura, nesse momento do feedback. O PC somente indicou um texto para leitura.

\section{Reflexões a partir da observação e do feedback formativo}

Ao buscar revelar possibilidades e desafios de realizar a formação em serviço, mediada pelo coordenador pedagógico na escola, essa investigação possibilitou compreender dois aspectos fundamentais deste tipo de formação a estratégia da observação da sala de aula e o feedback formativo.

A observação da sala de aula no estudo realizado desempenhou um papel fundamental para ter elementos a serem discutidos no feedback formativo, foi a partir dela que se identificaram concepções do professor relacionadas ao uso do material didático, à escolha das atividades, ao aprofundamento dos conteúdos apresentados, à competência e às hipóteses de aprendizagem de seus estudantes. Concepções merecedoras da atenção para superar alguns "preconceitos" relacionados à modalidade da EJA.

Vale ressaltar que a identificação dessas concepções pelo observador não foi feita a partir dos itens explícitos na grade de observação sugerida pela SEE, mas sim a partir dos seus conhecimentos sobre os assuntos. Assim sendo, percebe-se um primeiro desafio à tarefa de observar, o observador tem que ser portador de saberes oriundos da prática profissional do professor, das experiências bem-sucedidas de processos de ensino e aprendizagem e de teorias da área da Educação e das didáticas especificas. Esse conjunto de saberes influencia o processo de observação, fazendo com que a observação realizada seja uma versão do que aconteceu em sala de aula na perspectiva do observador, e não necessariamente um retrato fiel da realidade.

O aspecto feedback formativo analisado nesse estudo revelou-se ser essencial para caracterizar o processo de formação em serviço esperado para o professor. É a partir dele que é possível serem propostas reflexões que podem ser disparadoras do processo de desenvolvimento profissional do professor. Um desafio percebido nesse estudo é o de superar um feedback confirmativo para um feedback do tipo corretivo, conforme defino por Reis (2011). As hipóteses de não ter acontecido esse tipo de feedback nesse estudo estão relacionadas à não formação específica do PC para ser formador de professor, e a sua pouca experiência profissional como 
professor e como coordenador pedagógico. Mesmo assim, foi possível identificar competências inatas do PC, que podem ter contribuído com a formação do professor.

\section{Referências Bibliográficas}

ALMEIDA, L; Placco V. O papel do coordenador pedagógico. Revista Educação.12, n.142, 2009.

BUSHMAN, J. Teachers as walkthrough partners. Educational leadership. London,2006.

CANDAU, V. Formação continuada de professores: tendências atuais. In: REALE, A. M. M. R; Freire. Política e Educação: ensaios. 6a ed. São Paulo: Cortez,2001.

CASSIANI, S. de B.; CALIRI, M.H.L.; PELÁ, N.T.R. A teoria fundamentada nos dados como abordagem da pesquisa interpretativa. Revista enfermagem, v. 4, n. 3, dezembro 1996.

D’AMBROSIO, U. Educação matemática: da teoria à prática. 23 ed. Campinas: Papirus, 2012.

DEMO, P. Atividades de aprendizagem: sair da mania do ensino para comprometer-se com a aprendizagem do estudante. Secretaria de Estado de Educação do Mato Grosso do Sul. SED/MS. Campo Grande, MS, 2018.

FAZENDA, I. C. A (Org.). Integração e interdisciplinaridade no ensino brasileiro: efetividade ou ideologia? São Paulo: Loyola, 1979.

FERNANDES, C. A. X ; TRALDI JR, A. Formação do Professor de Matemática Mediada pelo Coordenador Pedagógico. REVEMOP, v. 3, p. 1-15, 2021.

FERNANDES, C. A. X. Formação em Serviço de um professor de matemática mediada pelo professor coordenador. 2020. Disseração (Mestrado em Ensino de Ciências e Matemática). Instituto Federal de Educação, Ciência e Tecnologia, Campus São Paulo. São Paulo, 2020.

FREITAS, A. V. Educação Matemática e Educação de Jovens e Adultos: estado da arte de publicações em periódicos (2000 a 2010), 2013. 360 f. Tese (Doutorado em Educação Matemática) - Pontífica Universidade Católica de São Paulo, São Paulo, 2013.

FONSECA, M. da C.F. R. Educação matemática de jovens e adultos: especificidades, desafios e contribuições. 3 ed. Belo Horizonte: Autêntica, 2012.

GOUVEIA, B; PLACCO, V. A formação permanente, o papel do coordenador pedagógico e a rede colaborativa. $O$ coordenador pedagógico e a formação centrada na escola. São Paulo: Edições Loyola, 2013.

KRAMER, S. Por entre as pedras: arma e sonho na escola. São Paulo:Ática, 1993. 
KURTOGLU,h, n. (2004, Julho). post-observation feedback as an instigator of teacher learning and change. iateFl tted sig e-newsletter. Obtido de:http://ttedsig.iatefl.org/resources/e-newsletter/ Featurearticles.pdf . Acesso em 27 de abril de 2011.

MARIN, A. J. Educação Continuada: introdução a uma análise de termos e concepções. Caderno CEDES. Campinas. São Paulo: Papirus, n.36, 1995.

NÓVOA, A. Formação de professores e trabalho pedagógico. Educa, 2002.

OLIVEIRA, C. A. D. O papel do (a) professor (a) coordenador (a) pedagógico (a) na formação em serviço dos (as) docentes do ensino fundamental II: uma análise dessa função em uma rede municipal de ensino do interior paulista. 2018. $124 \mathrm{f}$. Dissertação (Mestrado em Educação) - Universidade Federal de São Carlos, São Carlos, SP, 2018.

OLIVEIRA, M. K. Vygotsky: aprendizado e desenvolvimento: um processo Sóciohistórico. São Paulo: Scipione, 2002.

PLACCO, V. Formação e Prática do Orientador e do Educador. $5^{\mathrm{a}}$. ed. CAMPINAS - SP: PAPIRUS, 2002.

REIS, P. Ministério da educação - conselho científico para a avaliação de professores, Lisboa. 2011.

SAMPAIO, M. M. O coordenador pedagógico e a formação continuada de professores em serviço: uma análise em escolas públicas da região metropolitana do estado de Sergipe. Dissertação (Mestrado em Educação) - Universidade Federal de Sergipe, São Cristóvão, SE, 2018.

São Paulo (Estado). Resolução SE 75, DE 30/12/2014. Dispõe sobre a função gratificada do Professor Coordenador.

SCHÖN, D. Formar professores como profissionais reflexivos. in a. nóvoa (ed.), Os professores e a sua formação. Lisboa: d. Quixote e instituto de inovação educacional,1992.

SILVA, P.S; TRALDI JR, A. Linguagem matemática no processo de aprendizagem de estudantes surdos. Revista da Sociedade Brasileira de Educação Matemática - Regional São Paulo. V.16, n.23. 2019.

SILVEIRA, D. T.; CÓRDOVA, F. P. A pesquisa científica. Métodos de pesquisa, v. 1, 2009.

SOUZA, L. R de. Formação continuada em serviço: do coordenador pedagógico ao professor: o caso da rede municipal de São Paulo. Dissertação (Programa de Mestrado em Gestão e Práticas Educacionais) - Universidade Nove de Julho, São Paulo, 2017. 